\title{
Education Policy Implementation: A Mechanism for Enhancing Primary Education Development in Zanzibar
}

\author{
Amran Said Suleiman*, Yen Yat, Issah Iddrisu \\ School of Public Affairs, University of Science and Technology of China, Hefei, China \\ Email:^amran@mail.ustc.edu.cn
}

How to cite this paper: Suleiman, A.S., Yat, Y. and Iddrisu, I. (2017) Education Policy Implementation: A Mechanism for Enhancing Primary Education Development in Zanzibar. Open Journal of Social Sciences, 5, 172-181.

https://doi.org/10.4236/jss.2017.53015

Received: January 23, 2017

Accepted: March 19, 2017

Published: March 22, 2017

Copyright $\odot 2017$ by authors and Scientific Research Publishing Inc. This work is licensed under the Creative Commons Attribution International License (CC BY 4.0).

http://creativecommons.org/licenses/by/4.0/

\begin{abstract}
The study assessed the implementation of the education policy for primary education in Zanzibar so as to enhance the quality of education as well as to ensure that every child has access to education. The descriptive statistics were employed to analyse the data from the period 2012-2016. The results indicated that the implementation of education policy in Zanzibar has a real influence on the access to education in primary schools. The number of students' enrolment and teachers increased remarkably over these periods; however, enrolment rates were fluctuated by genders and geographical distributions. The lowest rate of enrolment was in the North "B" which was $72.0 \%$ compared with other districts. The results also revealed that dropout rate was reasonable with $6.87 \%$. The paper suggested that the MoEVT collaborate with the other education partners to strengthen the capacity of the teachers so as to ensure the quality of education in Zanzibar.
\end{abstract}

\section{Keywords}

Education Policy, Policy Implementation, Primary Education, Enrolment, Gender, Zanzibar

\section{Introduction}

Education is one of the fundamental rights of individuals; therefore, the government of a country needs to develop and strengthen educational policy and quality as well as to ensure that everyone has equal access to basic education [1]. The improvement of access and quality of education in the world is becoming as an essential factor in development [2], whereas the basic education (primary school), is acknowledged as a foundation of the higher educational development 
for every country [3]. To fulfill this goal, governments introduce several policies and procedures; however, it requires some reforms and participation from the politician, policymakers, and other stakeholders to re-examine educational policy so that it can lead to multiplication and betterment of the reforms [4]. Educational reforms actually focus on accountability [5] [6]. A positive educational development and reform is very challenging and needs more effort and strategy on how to use and utilise the resources effectively as such it can achieve the educational goals. Inevitably, to formulate the education policy faces many policy challenges, including inter alia, significant budgetary constraints, intermingling of other public institutions on its implementation, limited capacity to provide excellent quality services [7].

It does not matter how hard it is; the government has to overcome these challenges in order to achieve its educational and development goals, like overcrowding in classes which affects the delivery of quality education in the classroom. The low rate of teacher inspection (almost once in three years) hence has led some teachers to be less careful in their work. Also, there is the shortage of mathematics and science teachers because many of them have an arts background. Furthermore, there is the scarcity of learning materials for children with special needs. The existence of double shift (morning and afternoon) results in having less teaching and learning time. School-based inspections by the head teachers are not done as directed by the Ministry. Owing to the absence of residential quarters for teachers in many schools, teachers have to travel a long distance to school. As a consequence, they tend to reach late and be tired and this reduces teacher-pupils contact hours [8]. The present study assesses the implementation of the education policy for primary education in Zanzibar so as to enhance the quality of education as well as to ensure that every child has access to education. Therefore, this study aimed to improve access to education at the primary level by assessing gender, age, and geographical distributions to the enrolment for primary education in Zanzibar from 2012-2016. The results of the study will contribute to the resolutions of the current challenges of policy as well as provide some mechanisms for a better implementation of the policy for primary education in Zanzibar.

\section{Scrutiny of Education Policy Implementation in Zanzibar}

Zanzibar, a semi-autonomous part of the United Republic of Tanzania, has to take responsibilities for the educational reforms, particularly for primary education; the government, thus, has introduced a new education policy in 2006 which was updated from the old educational policy of 1991 and 1995 according to a request and demand from the stakeholders. The main goal of the policy is to provide a high quality of education in Zanzibar. However, the policy faces several challenges since the implementation has started although the government has tried all its best to take off those challenges to achieve a number of universally cherished goal [9]. Ministry of Education and vocational Training (MoEVT) in Zanzibar has the statutory power to make sure that education policy is imple- 
mented and accomplished in accordance with the timeframe. In order to implement Zanzibar Education Policy, the MoEVT provided Zanzibar Education Development Programme (ZEDP) in 2008 with some specific goals and objectives and drew up plans of action for the 8-year period of policy (2008/09 - 2015/16). Key issues have been identified in the ZEDP, including a deal with access, equity, quality and relevance [10]. The MoEVT continues to implement its education policy of 2006 which is going to the pick in 2018. Although any success binds with challenges and some goals have not much implemented, the government has implemented and achieved numerous goals of the policy to be encouraged.

Some studies have already analysed and made some assessments of education policy in general. Like Education Situation Analysis Final report January 2016 [11], Zanzibar Improving Students' Prospects Project (ZISP) April, 2015 [12] and Education for All Assessment 2001-2013 Zanzibar July, 2014 [8]. However, they have left a specific and discussion on the educational policy for primary education. As a result the researchers instigate to make the research on that perspective.

\section{Methodology}

\subsection{Background of Education System in Zanzibar}

The numerous stakeholders criticized the old system of education for primary education in Zanzibar whose pupils took several years to complete the elementary level. The system required 7 years for Standard $1-7$ or primary level. The students needed to spend 2 years for Form 1 - 2 or lower secondary level, 2 years for Form 3 - 4 or upper secondary level, and 2 years for Form 5 - 6 or advanced level. Students must pass the exam to go up to another level. The new system is 2-6-4-2-3+ which means 2 years of pre-primary education, 6 years of primary education, 4 years of the ordinary level, 2 years of advanced level and a minimum of 3 years of higher education. The school age for primary level had also changed from 7 to 6 years old [10]. Also, the MoEVT has introduced the English language as the medium of instruction for mathematics and science subject from standard 5.

Primary education in Zanzibar provides free education for age 6 - 11. The aim is to reduce the burden on parents by removing voluntary contributions at pre-primary and primary levels and ensuring that every school-aged child has access to education equally without any form of discrimination. However, people and societies are encouraged to contribute to the building of classrooms, stationery and other financials [11]. This aim is consistent with Article 10 of Chapter two of the Zanzibar's constitution of 1984 that provides fundamental objectives and directive principles for basic education. Meanwhile, in order to ensure a successful implement of the constitution, some other laws such as the Education Act No 6 of 1982, and the Children's Act (2011) were adopted to guarantee that children have full right to education [2] [13]. Except these laws, there are several important documents that the MoEVT has been developing to support the educational reforms such as Zanzibar Vision 2020, Millennium De- 
velopment Goal (MDGs), Zanzibar Growth and Poverty Reduction Strategy II (Swahili acronym MKUZA II) as well as other international promises of education such as education for all by the year 2015 [9]. This education policy has its term which will be ended in 2018. It has been noticed that the MoEVT has done a lot of reform for the quality of education in Zanzibar; however, many challenges are still needed to deal with for future success and reforms.

\subsection{Data Collection and Analysis}

It was a review-based study aimed to assess the implementation of the education policy for the primary school. According to the 2006 education policy, levels of the primary school are starting from standard $1-6$, however, the policy itself is in the transition period and in 2016 a new reform of combination of students who have graduated from standard 6 and 7 into Form 1 . The researchers used secondary data from different sources, including the budget speeches [14] [15], reports and analyses from the MoEVT. Due to a lack of data, the study would make an assessment of the data from 2012-2016. The data analysis based on gender, age, level of study, and geographical distributions of the schools. Indeed, some other relevant literatures are used to complete this study. The data collected were disseminated through some figures and tables for a thoughtful concept.

\section{Results and Discussion}

\subsection{Access to Education in Primary Level}

Figure 1 displayed detail gross enrolment level in Primary Schools. The data showed that the enrolment in both public and private school in the last two years were increasing, but the data of 2016 indicated that to some extent was decrease. The enrolment surpasses more than hundred percent.

In 2016, some fewer pupils met the age of enrolment for education; however, an average of entire enrolment was increasing by $0.71 \%$ for primary school each year from 2012-2016. This progress level is successful concurrently with an expansion of infrastructure and teachers. The aim of the MoEVT is to guarantee the quality of primary education and ensure that every school-aged pupil can

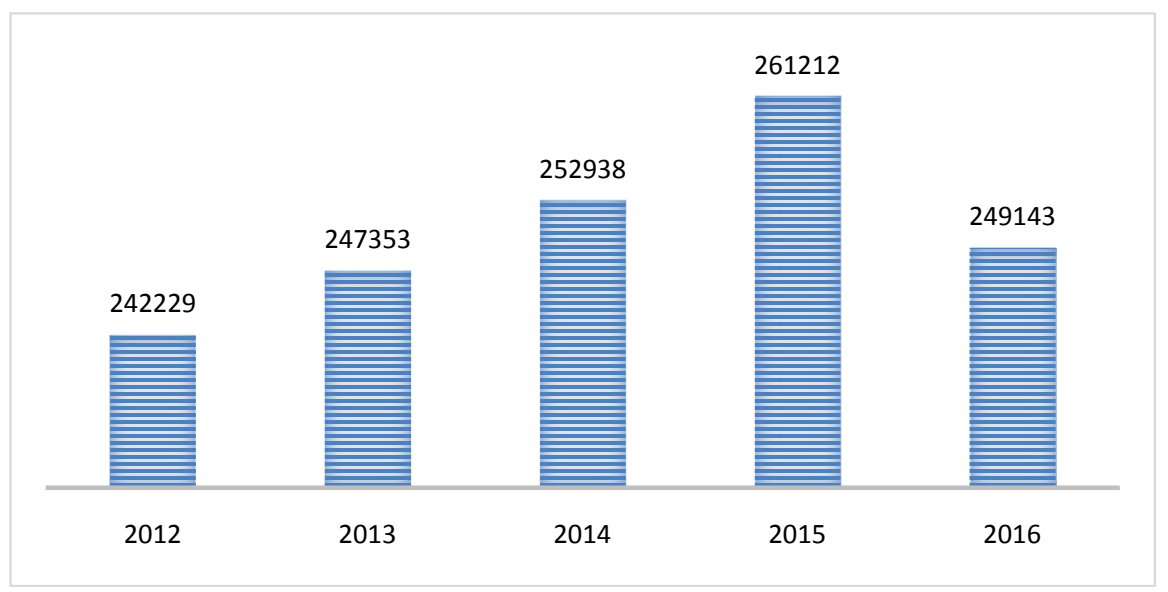

Figure 1. The gross enrolment level in primary schools (Source: [15]). 
access to primary education to fulfil their dream. It is a remarkable achievement that the rate of enrolment was increasing from $90 \%$ in 2010 to $95 \%$ in 2016 and the MoEVT projected $100 \%$ of enrolment for Standard I by 2016 [10] [11]. On the other hand, the growing rate of enrolment is quite different with the study of Murphy et al. (2016) who clarify increasing gradually by nearly $3 \%$ each year. The aim of the MoEVT is consistent with an idea of Etor et al. (2013), who explained that development of primary education it is really paramount as is set a foundation of all another level of education [3].

\subsection{Access to Education by Age}

Because the researchers could not find an available data about different ages of enrolment for each Standard of primary education, so that the enrolment of the pupils in each year just was in general ages of 7 - 13 years old for 2012-2015 and 6 - 11 years old for 2016. Figure 2 provided the overall enrolment of pupils which were remarkably grown from 199,310 in 2012 to 265,591 in 2015. The number of enrolment in 2016 was a bit lower than in 2015 due to the educational reform when the age of enrolment was lower to 6 years old instead of 7 years old before the reform. However, the trend was not so strong but has a high impact on the educational development and reform. Figure 2 also indicated the trend of overall enrolment regarding age was 3.5\% per year from 2012-2016.

The challenges of enrolment remain due to some parents who are in remote areas are late to enroll their children in primary education at the school-age as it is required by the educational policy. The reasons why parents are late to enroll may be from the family resources and the distance of school to the pupils' home of residence. On the other hand, the poor awareness of educational policy and reform by the community as well as those parents would also lead to the belated enrolment of their children to school. Thus, a wide dissemination of the policy would be crucial to the development and reform of the policy.

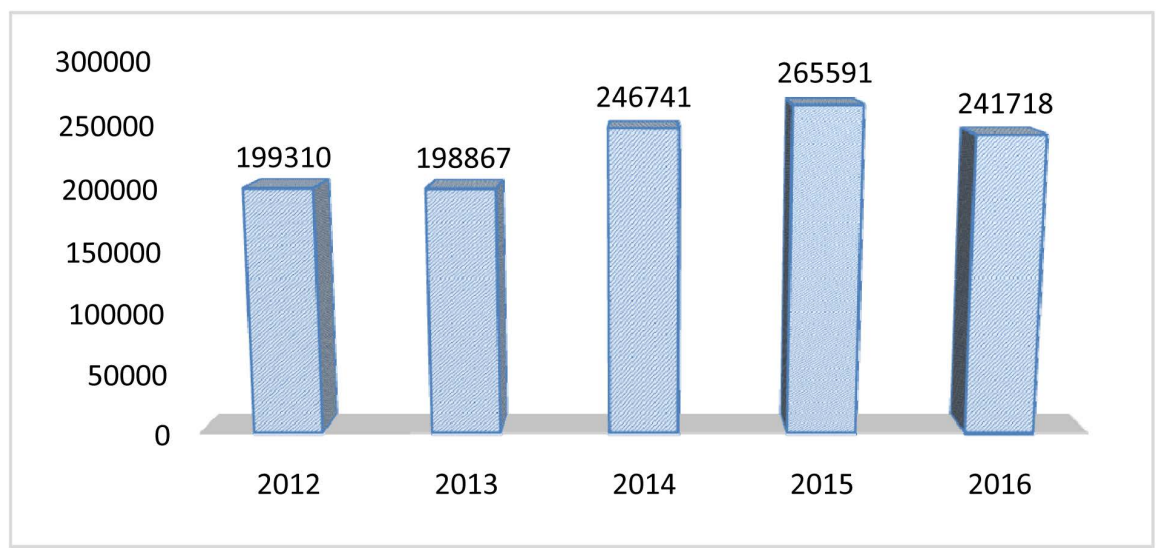

Figure 2. The growth of the age students in access to education in primary schools (Source: [15]).

\subsection{The Growth Enrolment Rate by Classes}

Figure 3 depicted the different growth rates of enrolment from Standard 1 - 7. 


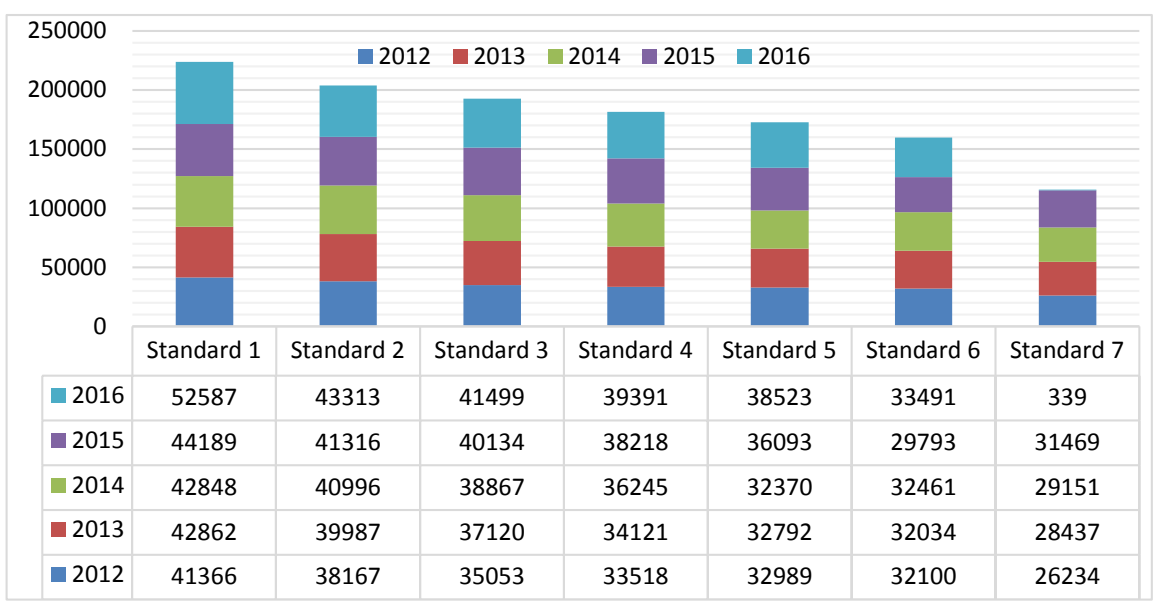

Figure 3. The growth of enrolment rate by classes from 2012-2016 (Source: [15]).

The number of students of each Standard has increased rapidly. For instance, there were 41,366 enrolled in Standard 1 in 2012, but it rose to 52,587 in 2016. Likely, for Standard 2, it grew from 38,167 in 2012 to 43,313 in 2016. However, it was noticed that for there was a bit decrease of enrolment for Standard 6 in 2015 to 29,793 compared with previous academic years. Remarkably, there were only 339 students enrolled in 2016 for Standard 7 at private primary schools while public primary schools have changed and combined this standard into Form 1 so that the data for Standard 7 in the public primary school vanished.

Looking at Figure 3 for Standard 1, there were 41,366 students enrolled for Standard 1 and these students would continue to Standard 2 in 2013 or to Standard 5 in 2016. The data showed that the number of students was decreased gradually from 41,366 in 2012 to 38,523 in 2016. In this sense, a number of dropout rates of students can be calculated by misusing a number of students of Standard 1 in 2012 by a number of students of Standard 5 in 2016. It revealed that there were 2843 or $6.9 \%$ of students had dropped out their study. Indeed, some students from private schools who studied in Standard 5 or 6 shifted to Standard 7 at the public schools for the national examination in order to qualify for a special class in secondary education and get an exemption from the national examination until Form 4. Also, some students shifted from one school to another without following the real procedures so that it was little hard for the MoEVT; therefore, to keep a real record of dropout rate [9]. However, the dropout rate of primary school students in Zanzibar is still acceptable while Murphy et al. 2016 argued that in general, more than 25\% of children dropout before finishing basic education [11].

\subsection{Access to Primary Education by Genders and Geographical Distributions}

Table 1 explained an access to primary education differentiated by genders and geographical distributions. It differed from one district and another where the rates of enrolment were distributed for throughout Zanzibar. Looking at 2012, the lowest rate of enrolment was in the North "B" which was $72.0 \%$ totally or 
Table 1. The gross enrolment rate of primary education by genders and geographical distributions.

\begin{tabular}{|c|c|c|c|c|c|c|c|c|c|c|c|c|c|c|c|c|c|c|}
\hline \multirow{2}{*}{ Districts } & \multicolumn{3}{|c|}{2012} & \multicolumn{3}{|c|}{2013} & \multicolumn{3}{|c|}{2014} & \multicolumn{3}{|c|}{2015} & \multicolumn{3}{|c|}{2016} & \multicolumn{3}{|c|}{ Total \% } \\
\hline & B & G & $\mathrm{T}$ & B & G & $\mathrm{T}$ & B & G & $\mathrm{T}$ & B & G & $\mathrm{T}$ & B & G & $\mathrm{T}$ & B & G & $\mathrm{T}$ \\
\hline Urban & 82.2 & 79.5 & 80.8 & 98.8 & 98.1 & 98.4 & 102.0 & 100.6 & 101.3 & 97.8 & 99.3 & 98.6 & 87.1 & 85.3 & 86.2 & 93.58 & 92.56 & 93.06 \\
\hline West & 76.2 & 76.7 & 76.5 & 196.4 & 197.9 & 197.2 & 102.5 & 102.2 & 102.4 & 89.5 & 86.9 & 88.1 & 103.4 & 101.2 & 102.3 & 113.6 & 112.98 & 113.3 \\
\hline North "A" & 93.7 & 83.0 & 88.2 & 106.5 & 122.1 & 114.0 & 103.9 & 109.4 & 106.7 & 153.5 & 104.4 & 123.8 & 106.5 & 105.0 & 105.7 & 112.82 & 104.78 & 107.68 \\
\hline North “B” & 70.3 & 73.8 & 72.0 & 99.9 & 108.4 & 104.0 & 74.6 & 72.8 & 73.7 & 68.1 & 68.1 & 69.5 & 82.9 & 74.8 & 78.8 & 79.16 & 79.58 & 79.6 \\
\hline Central & 110.2 & 114.2 & 112.2 & 122.5 & 132.0 & 127.1 & 121.9 & 123.9 & 122.9 & 117.5 & 117.5 & 114.5 & 125.4 & 122.7 & 124.1 & 119.5 & 122.06 & 120.16 \\
\hline South & 124.5 & 105.2 & 115.0 & 126.8 & 121.9 & 124.4 & 127.3 & 129.0 & 128.1 & 121.9 & 121.9 & 119.9 & 119.8 & 122.0 & 120.8 & 124.06 & 120 & 121.64 \\
\hline Micheweni & 75.0 & 81.5 & 78.1 & 104.0 & 114.7 & 109.2 & 85.8 & 91.7 & 88.6 & 89.1 & 89.1 & 88.3 & 85.7 & 88.1 & 86.9 & 87.92 & 93.2 & 90.22 \\
\hline Wete & 106.9 & 109.9 & 108.4 & 102.7 & 105.9 & 104.2 & 110.9 & 109.9 & 110.4 & 112.9 & 112.9 & 113.3 & 123.4 & 121.3 & 122.4 & 111.36 & 111.98 & 111.74 \\
\hline Chake Chake & 109.2 & 97.3 & 103.2 & 117.7 & 117.9 & 117.8 & 108.1 & 107.0 & 107.6 & 103.6 & 103.6 & 109.7 & 121.3 & 118.9 & 120.1 & 111.98 & 108.94 & 111.68 \\
\hline Total & 89.1 & 87.5 & 88.3 & 121.8 & 127.1 & 124.4 & 102.2 & 102.9 & 102.5 & 96.4 & 96.4 & 98.4 & 115.9 & 102.0 & 103.1 & 105.08 & 103.18 & 103.34 \\
\hline
\end{tabular}

Note: $\mathrm{B}=$ boys, $\mathrm{G}=$ girls, and $\mathrm{T}=$ total. Source: [8] [14] [15].

$70.3 \%$ for boys and $73.8 \%$ for girls. Basically, the rate of enrolment is differentiated by genders, and the rate of enrolment for male or boy students is higher than female or girl students [16] [17] [18]. It was likely the same for the rates of enrolment of primary school students in Zanzibar where the rates of enrolment for boys were higher than girls for each year from 2012-2016. However, it was worth nothing that rates of enrolment for girls in the Central and Wete were higher than boys in 2012 as well in 2013 while the majority of the districts in 2013, the rates of enrolment for girls were higher than boys. For example, in the North "A", there was $122.1 \%$ of enrolment for girls which was higher than $106.4 \%$ for boys. There are two districts where the MoEVT needs to pay more attentions, which are the North " $\mathrm{B}$ " and Micheweni for which these two districts were remarkably noticed that the rates of enrolment were the lowest compared with other districts since 2012 up to 2016 with $79.6 \%$ and $90.22 \%$ respectively. For instance, there was only $72.0 \%$ for the North "B" and $78.1 \%$ for Micheweni of total male and female students enrolled in primary schools in 2012. It is not much difference between the two districts in 2016 that the total rates of enrolment were $78.8 \%$ for the North "B" and $86.9 \%$ for Micheweni. The lowest rates of enrolment of the areas because they are ones among the poor districts in Zanzibar. On the other hand, South and Central districts became the highest overall enrolment rate from 2012-2016 which were $121.64 \%$ in South district and $120.16 \%$ for the Central district. By comparing the differences in the geographical distributions and genders, the MoEVT can improve the lowest developed districts and continue to improve the district's successful development so that it can be sure that every child can access to education equally without any barrier regarding areas and genders.

\subsection{Capacity Development of the Teachers}

The capacity development of teachers for both public and private primary school 
and secondary school from 2012-2016 was explained in Table 2. Due to lack of teachers, both public and private schools in Zanzibar employed some teachers without a sort of pedagogy training; however, the new education reform has paid much attention to the capacity building and development for all levels of teachers. Table 2 showed that the number of untrained teachers was being reduced yearly; in contrast, the number of trained teachers was being increased yearly. For example, there were 496 untrained teachers in 2012, but these figures were reduced to 93 in 2016 while there were 8645 trained teachers in 2012 and the number of trained teachers rose up to 9857 in 2016. It was not much different for private schools where the number of trained teachers was also increasing from 831 in 2012 to 1638 in 2016; however, a number of untrained teachers were not much changed from 364 in 2012 and 405 in 2016. The number of untrained teachers in private schools was not changed due to an increase in a number of private schools so that demand for teachers was also increasing while a number of qualified teachers were still lagged behind the demand. It is also a big challenge for the MoEVT to train and offer sufficient teachers due to the new reform of the policy as well as an increase in a number of new students and schools so that demand for newly qualified teachers is still needed [8].

Table 2. The growth of number of teachers in primary and secondary level.

\begin{tabular}{|c|c|c|c|c|c|c|c|c|c|c|c|c|}
\hline \multirow{2}{*}{ Years } & \multicolumn{4}{|c|}{ Public Schools } & \multicolumn{4}{|c|}{ Private Schools } & \multicolumn{4}{|c|}{ Total } \\
\hline & Trained & Untrained & Total & $\%$ of untrained & Trained & Untrained & Total & $\%$ of untrained & Trained & Untrained & Total & $\%$ of untrained \\
\hline 2012 & 8645 & 496 & 9141 & 5.4 & 831 & 364 & 1195 & 30.5 & 9476 & 860 & 10,336 & 8.3 \\
\hline 2013 & 9503 & 391 & 9894 & 4.0 & 1178 & 346 & 1524 & 22.7 & 10,681 & 737 & 11,418 & 6.5 \\
\hline 2014 & 9832 & 129 & 9961 & 1.3 & 1225 & 407 & 1632 & 24.9 & 11,057 & 536 & 11,593 & 4.6 \\
\hline 2015 & 9942 & 89 & 10,031 & 0.9 & 1441 & 354 & 1795 & 19.7 & 11,383 & 443 & 11,826 & 3.7 \\
\hline 2016 & 9857 & 93 & 9950 & 0.9 & 1638 & 405 & 2042 & 19.8 & 11,495 & 498 & 11,993 & 4.2 \\
\hline
\end{tabular}

Note: These data are not obtained specifically in primary school teachers. Also, this data excluded pre-schools teachers and Karume College. Source: [15].

\section{Conclusion and Recommendation}

The implementation of the education policy showed a positive change and success from 2012-2016. It was noticed that the number of enrolment increased rapidly; however, the enrolment rates were different by genders and from one district to another. Although the dropout rates were still acceptable for Zanzibar, the MoEVT needs pay more intention to some districts such as the North "B" and Micheweni where rates of enrolment were still low. The MoEVT also has concentrated on the capacity development of its staff so as to ensure the quality of education for all. In short, the MoEVT has done well to improve access to basic education at primary education.

The study suggested that the MoEVT implement the education policy by paying more attention to gender equity and geographical distributions of the access to basic education of children. The MoEVT also needs to improve the awareness of the communities so as to bring their pupils to enroll at the eligible age. Also, MoEVT should continue to collaborate with other educational institutions and 
development partners to provide refresher courses to strengthen the capacity of the teachers so that the quality of education can also be ensured. The refresher courses are paramount especially in this time of globalisation where different teaching methods are changing time to time. Moreover, inspection is needed from time to time to ensure the quality of education to enhance primary schooling as the foundation of higher education.

\section{Acknowledgements}

The study was supported by the Chinese Scholarship Council (CSC). The authors also owned sincere thanks to the support and advice from the Dean of the School of Public Affairs, University of Science and Technology of China. The authors declare that there is no conflict of interest to disclose for this paper.

\section{References}

[1] Cankaya, S., Kutlu, Ö. and Cebeci, E. (2015) The Educational Policy of European Union. Procedia-Social and Behavioral Sciences, 174, 886-893. https://doi.org/10.1016/j.sbspro.2015.01.706

[2] MoEVT (2007) Zanzibar Education Development Programme (ZEDP) 2008/092015/16 DRAFT 3. Minisrty of Education and Vocational Training Zanzibar, 1-100.

[3] Etor, C.R., Mbon, U.F. and Ekanem, E.E. (2013) Primary Education as a Foundation for Qualitative Higher Education in Nigeria. Journal of Education and Learning, 2, 155. https://doi.org/10.5539/jel.v2n2p155

[4] Levin, B. (1998) An Epidemic of Education Policy: (What) Can We Learn from Each Other? Comparative Education, 34, 131-141. https://doi.org/10.1080/03050069828234

[5] Hopkins, D. and Levin, B. (2000) Government Policy and School Development. School Leadership \& Management, 20, 15-30. https://doi.org/10.1080/13632430068851

[6] Fink, D. (2003) The Law of Unintended Consequences: The "Real" Cost of TopDown Reform. Journal of Educational Change, 4, 105-128. https://doi.org/10.1023/A:1024783324566

[7] Spillane, J.P., Reiser, B.J. and Reimer, T. (2002) Policy Implementation and Cognition: Reframing and Refocusing Implementation Research. Review of Educational Research, 72, 387-431. https://doi.org/10.3102/00346543072003387

[8] UNESCO and MoEVT (2014) Education for All Assessment 2001-2013 Executive Summary Zanzibar. Minisrty of Education and Vocational Training Zanzibar, $1-176$.

[9] MoEVT (2006) Zanzibar Education Policy. Ministry of Education and Vocational Training Zanzibar, 1-75.

[10] MoEVT (2016) Review of the Zanzibar Education Development Programme (ZEDP): 2008/2009-2015/2016. Ministry of Education and Vocational Training Zanzibar, 1-97.

[11] Murphy, P., Rawle, G. and Ruddle, N. (2016) Zanzibar Education Situation Analysis. Final Report, Oxford Policy Management, 1-168.

[12] MoEVT (2015) Environmental and Social Management Framework (ESMF): Zanzibar Improving Students' Prospects Project (ZISP). Ministry of Education and Vocational Training Zanzibar, 1-75. 
[13] Right to Education Project (2015) Right to Education Country Factsheet: United Republic of Tanzania. 3-25.

[14] MoEVT (2014) The Speech of the Minister of the Ministry of Education and Vocational Training Zanzibar, Budget Speech 2014/2015 Hotuba ya Waziri wa Elimu na Mafunzo ya Amali kuhusu Makadirio ya Mapato na Matumizi ya Fedha kwa mwaka wa fedha 2014/15 (Kiswahili). Revolutionary Government of Zanzibar, Revolutionary Government of Zanzibar, 1-82.

[15] MoEVT (2016) The Speech of the Ministries of the Ministry of Education and Vocational Training Zanzibar, Budget Speech 2016/2017 Hotuba ya Waziri wa Elimu na Mafunzo ya Amali kuhusu Makadirio ya Mapato na Matumizi ya Fedha kwa mwaka wa fedha 2016/17 (Kiswahili). Revolutionary Government of Zanzibar, 1-55.

[16] Bowman, M.J. and Anderson, C.A. (1980) The Participation of Women in Education in the Third World. Comparative Education Review, 24, 513-532.

https://doi.org/10.1086/446137

[17] Wells, R. (2009) Gender and Age-Appropriate Enrolment in Uganda. International Journal of Educational Research, 48, 40-50. https://doi.org/10.1016/j.ijer.2009.03.002

[18] Bleske-Rechek, A. and Browne, K. (2014) Trends in GRE Scores and Graduate Enrollments by Gender and Ethnicity. Intelligence, 46, 25-34.

https://doi.org/10.1016/j.intell.2014.05.005

\section{Scientific Research Publishing}

\section{Submit or recommend next manuscript to SCIRP and we will provide best} service for you:

Accepting pre-submission inquiries through Email, Facebook, LinkedIn, Twitter, etc. A wide selection of journals (inclusive of 9 subjects, more than 200 journals) Providing 24-hour high-quality service User-friendly online submission system Fair and swift peer-review system Efficient typesetting and proofreading procedure Display of the result of downloads and visits, as well as the number of cited articles Maximum dissemination of your research work

Submit your manuscript at: http://papersubmission.scirp.org/ Or contact jss@scirp.org 